\title{
Changes in the Composition of Fatty Acids and Lipofuscin-Like Pigments During Development of Rat Heart
}

\author{
J. WILHELM ${ }^{1}$, J. IVICA ${ }^{1}$, Z. VESELSKÁ ${ }^{1}$, J. UHLÍKK $^{1,2}$, L. VAJNER $^{1,2}$ \\ ${ }^{1}$ Institute of Physiology, Czech Academy of Sciences, Prague, Czech Republic, ${ }^{2}$ Department \\ of Histology and Embryology, Second Medical Faculty, Charles University, Prague, Czech \\ Republic
}

Received September 24, 2014

Accepted February 17, 2015

On-line March 24, 2015

\begin{abstract}
Summary
Postnatal heart development is characterized by critical periods of heart remodeling. In order to characterize the changes in the lipophilic fraction induced by free radicals, fatty acids and their oxidized products, lipofuscin-like pigments (LFP), were investigated. Fatty acids were analyzed by gas chromatography and LFP were studied by fluorescence techniques. A fluorophore characterized by spectral methods was further resolved by HPLC. Major changes in the composition of fatty acids occurred immediately after birth and then during maturation. Fluorescence of LFP changed markedly on postnatal days $1,4,8$, and 14 , and differed from the adult animals. LFP comprise several fluorophores that were present since fetal state till adulthood. No new major fluorophores were formed during development, just the abundances of individual fluorophores have been modulated which produced changes in the shape of the spectral arrays. HPLC resolved the fluorophore with excitation maximum at $360 \mathrm{~nm}$ and emission maximum at $410 \mathrm{~nm}$. New chromatographically distinct species appeared immediately on postnatal day 1 , and then on days 30 and 60 . Consumption of polyunsaturated fatty acids immediately after birth and subsequent formation of LFP suggests that oxidative stress is involved in normal heart development.
\end{abstract}

\section{Key words}

Development • Fatty acids • Free radicals • Heart • Lipofuscinlike pigments

\section{Corresponding author}

J. Wilhelm, Department of Membrane Receptor Biochemistry, Institute of Physiology, Czech Academy of Sciences, Vídeňská 1083, 14220 Prague 4, Czech Republic.

E-mail: wilhelm@biomed.cas.cz

\section{Introduction}

At birth, heart oxygen concentration undergoes dramatic changes. After delivery, arterial $\mathrm{PO}_{2}$ increases more than threefold (from 30 to $100 \mathrm{~mm} \mathrm{Hg}$ ) and arterial $\mathrm{O}_{2}$ saturation increases from 18 to $97 \%$ (Mitchell and Van Kainen 1992, Webster and Abela 2007). These changes in the tissue adapted to the fetal oxygen levels create conditions for an oxidative stress. This transition is accompanied by a change in nutrition because transplacental supply of nutrients is interrupted and mother's milk nutrition is not yet fully developed (Kuma et al. 2004).

The situation after birth is analogical to a hyperoxic stress produced by placing animals from normoxia to hyperoxia. Hyperoxic stress in adults was documented as a cause of heart oxidative damage (Nohl et al. 1981) and accordingly, an increase in the reactive oxygen species (ROS) in the heart after birth is therefore to be expected. Production of ROS in mouse heart significantly increased on postnatal day 4 and 7 in comparison with the postnatal day 1 . Similarly, a marker for oxidative base modification in DNA, 8-oxo-7,8dihydroguanine was increased on postnatal day 4 and 7 , thus documenting an oxidative damage in the developing mouse heart (Puente et al. 2014).

Earlier study showed ROS-mediated oxidative damage to DNA in rat liver, kidney, and skin during the first few hours after normal birth. Lungs were not affected. The lesions were considered substantial, having been similar to or exceeding the levels found in 24-month 
old rats (Randerath et al. 1997). The concept of oxidative stress after normal birth was supported by the finding of pronounced neonatal decrease in the hepatic GSH/GSSG ratio in rats (Sastre et al. 1994).

The critical component controlling many cellular functions is the composition of fatty acids. Changes in their abundances influence vast range of qualities ranging from membrane fluidity to enzyme activities. Neonatal stress and increased cardiac function was found to influence the profile of fatty acids in neonatal rat heart (Gudmundsdottir and Gudbjarnason 1983, Novák et al. 2006).

There are several possibilities to assess the extent of oxidative stress. We have chosen for this study the end products of lipid peroxidation, the so called lipofuscin-like pigments (LFP). These fluorescent lipophilic substances are widely used as markers of oxidative damage (Jamieson 1991, Shimasaki 1994, Vasankari et al. 1995, Wilhelm and Herget 1999), because they are relatively stable and long-lived. The subject has been recently reviewed (Ivica and Wilhelm 2014). In several works (Del Roso et al. 1991, Ikeda et al. 1985, Muscari et al. 1990) higher accumulation of LFP was observed in the rat heart during older periods of postnatal development. On the other hand, in another study a higher level of LFP was described in the hearts of weaning rats as compared with 19-month-old rats (Csallany et al. 1986).

We have found increased LFP concentrations corresponding to augmented ROS production in the rat heart shortly after birth in our previous studies (Oštádalová et al. 2010, 2007). The present study is aimed at the changes in the composition of fatty acids and analysis of LFP components in relation to critical developmental periods.

\section{Methods}

The study was conducted in accordance with the Guide for the Care and Use of Laboratory Animals published by the US National Institutes of Health (NIH publication No. 85-23, revised 1996). Experiments were approved by the Animal Protection Expert Commission of the faculty.

\section{Animals}

Twelve pregnant female Wistar rats were used throughout the experiments. They had free access to water and standard laboratory diet. The offsprings (a total of 65 neonates) of both sexes were investigated 1 day before birth (group F, mean weight $4.32 \pm 0.30 \mathrm{~g}$ ), and then on days 1 (group D1, mean weight $6.29 \pm 0.41 \mathrm{~g}$ ), 2 (group D2, mean weight $7.91 \pm 0.23 \mathrm{~g}$ ), 4 (group D4, mean weight $10.15 \pm 0.99 \mathrm{~g}$ ), 8 (group D8, mean weight $16.64 \pm 2.00 \mathrm{~g}$ ), 14 (group D14, mean weight $25.68 \pm 1.79$ g), 30 (group D30, mean weight $110.00 \pm 2.5 \mathrm{~g}$ ), and 60 (group D60, mean weight $275.15 \pm 7.07 \mathrm{~g}$ ) of postnatal life.

On the sampling day, rats were weighed and sacrificed under general anesthesia (Thiopental, $40 \mathrm{mg}$ $\mathrm{kg}^{-1}$ b.w., i.p., VUAB Pharma a.s., Roztoky, Czech Republic) by decapitation (groups F, D1, D2, D4, D8) or by cutting the spinal cord (groups D14, D30, D60). In the $\mathrm{F}$ group, mothers were anaesthetized. Hearts were exenterated and immediately frozen in the liquid nitrogen.

\section{Fatty acids analysis}

Total lipids were extracted according to (Dodge and Phillips 1967) using equimolar mixture of methanolchloroform. Individual lipid classes were separated by thin-layer chromatography $(0.25 \mathrm{~mm}$ Silica Gel, Macherey-Nagel, Düren, Germany) with a mobile phase of heptane-diethylether-acetic acid (80:20:1, v/v/v) according to (Tvrzická et al. 2002). The phospholipid fraction was transformed to methyl esters by transesterification by methanolic solution of $\mathrm{BF}_{3}$ (Dodge and Phillips 1967, Gercken et al. 1972). Methylesters were extracted twice into pentane, concentrated and stored at $-20{ }^{\circ} \mathrm{C}$. Fatty acids methylesters were resolved on a gas chromatograph Agilent 6890N (Agilent Technologies, Santa Clara, USA) equipped with flame ionization detector using a capillary column Famewax ( $30 \mathrm{~m} \mathrm{x} 0.25 \mathrm{~mm}, 0.25 \mu \mathrm{m}$, Restek, Bellefonte, USA), and hydrogen as a carrier gas. The temperature programme of the column started at $60^{\circ} \mathrm{C}$ for $2 \mathrm{~min}$, then the column was warmed up at the speed of $10^{\circ} \mathrm{C} \mathrm{min}^{-1}$ to $240^{\circ} \mathrm{C}$. The final temperature was kept for $5 \mathrm{~min}$. Fatty acids methylesters were identified on the basis of their retention times compared to the retention times of standards. The relative abundance of given fatty acid was calculated as an average of the percentage of the peak area. Fatty acids analyses were run in pentaplicates. The statistical evaluations were made using ANOVA with Scheffe post-hoc test, and the results are shown as means \pm SD. 
Table 1. The abundances of fatty acids in the rat heart lipophilic fraction in the course of ontogenesis.

\begin{tabular}{|c|c|c|c|c|c|c|c|c|}
\hline \multirow{2}{*}{$\begin{array}{l}\text { Fatty } \\
\text { acid }^{\mathrm{a}}\end{array}$} & $\mathbf{F}$ & D1 & D2 & D4 & D8 & D14 & D30 & D60 \\
\hline & \multicolumn{8}{|c|}{ Relative Abundance \% } \\
\hline C 14:0 & $0.9 \pm 0.15$ & $3.0 \pm 0.40^{* *}$ & $0.5 \pm 0.09$ & $0.8 \pm 0.10$ & $1.0 \pm 0.20$ & $1.0 \pm 0.15$ & $0.3 \pm 0.03^{*}$ & $0.1 \pm 0.02^{* *}$ \\
\hline C 16:0 & $20.6 \pm 0.92$ & $16.4 \pm 0.80$ & $19.4 \pm 0.88$ & $18.8 \pm 0.75$ & $18.5 \pm 0.81$ & $19.0 \pm 0.95$ & $22.6 \pm 1.05$ & $13.5 \pm 0.65^{*}$ \\
\hline C $16: 1, n-7$ & $1.1 \pm 0.18$ & $1.3 \pm 0.15$ & $0.8 \pm 0.10$ & $0.5 \pm 0.03^{*}$ & $0.3 \pm 0.03^{* *}$ & $0.3 \pm 0.02^{* *}$ & $0.4 \pm 0.03^{* *}$ & $0.3 \pm 0.02^{* *}$ \\
\hline C 18:0 & $20.0 \pm 0.88$ & $15.1 \pm 0.75^{*}$ & $20.0 \pm 0.90$ & $20.9 \pm 0.85$ & $22.0 \pm 0.80$ & $21.4 \pm 0.72$ & $23.2 \pm 1.10$ & $21.6 \pm 0.75$ \\
\hline$C 18: 1, n-9$ & $10.2 \pm 0.35$ & $22.8 \pm 0.48^{* *}$ & $9.9 \pm 0.34$ & $7.0 \pm 0.28$ & $5.3 \pm 0.30^{*}$ & $4.4 \pm 0.25^{* *}$ & $15.9 \pm 0.35^{*}$ & $6.1 \pm 0.26^{*}$ \\
\hline C 18:1,n-7 & $4.3 \pm 0.20$ & $4.6 \pm 0.25$ & $4.6 \pm 0.18$ & $4.5 \pm 0.15$ & $4.2 \pm 0.20$ & $4.1 \pm 0.13$ & $3.4 \pm 0.22^{*}$ & $4.3 \pm 0.15$ \\
\hline C 18:2, n-6 & $7.8 \pm 0.42$ & $12.0 \pm 0.40^{* *}$ & $6.6 \pm 0.31$ & $5.7 \pm 0.35^{*}$ & $5.9 \pm 0.30^{*}$ & $5.9 \pm 0.25^{*}$ & $11.2 \pm 0.35^{* *}$ & $21.7 \pm 0.50^{* *}$ \\
\hline C 18:3.n-6 & $1.0 \pm 0.08$ & $2.2 \pm 0.10^{* *}$ & $0.0 \pm 0.00^{* *}$ & $0.3 \pm 0.02^{* *}$ & $0.1 \pm 0.01^{* *}$ & $0.2 \pm 0.01^{* *}$ & $0.0 \pm 0.00^{* *}$ & $0.2 \pm 0.01^{* *}$ \\
\hline C 18:3.n-3 & $1.1 \pm 0.03$ & $1.2 \pm 0.05$ & $0.9 \pm 0.04$ & $0.6 \pm 0.05^{*}$ & $0.1 \pm 0.01^{* *}$ & $0.7 \pm 0.05^{*}$ & $0.1 \pm 0.01^{* *}$ & $0.1 \pm 0.01^{* *}$ \\
\hline C 20:0 & $1.8 \pm 0.10$ & $1.1 \pm 0.08^{*}$ & $1.3 \pm 0.07^{*}$ & $0.8 \pm 0.06^{* *}$ & $0.2 \pm 0.01^{* *}$ & $0.7 \pm 0.04^{* *}$ & $0.2 \pm 0.01^{* *}$ & $0.2 \pm 0.01^{* *}$ \\
\hline C 20:4, n-6 & $20.2 \pm 1.10$ & $14.0 \pm 0.85^{* *}$ & $23.2 \pm 0.95$ & $25.2 \pm 1.18^{*}$ & $25.0 \pm 1.55^{*}$ & $22.5 \pm 1.15$ & $13.9 \pm 0.77^{* *}$ & $19.6 \pm 0.68$ \\
\hline C 22:5, n-3 & $3.6 \pm 0.03$ & $0.0 \pm 0.00^{* *}$ & $3.3 \pm 0.02$ & $3.2 \pm 0.02$ & $3.3 \pm 0.03$ & $4.4 \pm 0.08$ & $0.7 \pm 0.04^{* *}$ & $1.6 \pm 0.07^{* *}$ \\
\hline C 22:6, n-3 & $7.5 \pm 0.25$ & $6.2 \pm 0.20^{*}$ & $7.2 \pm 0.20$ & $9.3 \pm 0.31^{*}$ & $12.3 \pm 0.35^{* *}$ & $14.0 \pm 0.40^{* *}$ & $14.6 \pm 0.32^{* *}$ & $8.8 \pm 0.30$ \\
\hline
\end{tabular}

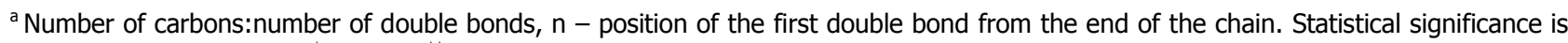
related to the fetal group, ${ }^{*} \mathrm{P}<0.05,{ }^{* *} \mathrm{P}<0.01$.

\section{Fluorescence analysis}

The technique described by (Goldstein and McDonagh 1976), as modified by (Wilhelm and Herget 1999), was used for the analysis of LFP in the heart. Approximately $30 \mathrm{mg}$ of frozen heart sample was weighed, chopped to fine pieces, and transferred into a glass-stoppered test tube containing $6 \mathrm{ml}$ of chloroformmethanol mixture $(2: 1, \mathrm{v} / \mathrm{v})$. After $1 \mathrm{~h}$ extraction on a motor-driven shaker, $2 \mathrm{ml}$ of double distilled water was added, the sample was agitated and the ensuing mixture was centrifuged (400 g, $10 \mathrm{~min}$ ). After centrifugation, the lower chloroform phase was separated and used for measurements.

Fluorescence excitation and synchronous spectra were measured on an Aminco-Bowman series 2 spectrofluorometer and recorded and analyzed using AB2 computer program that also organized the spectra into tridimensional spectral arrays. The excitation spectra were measured in the range of 250-400 $\mathrm{nm}$ for emission adjusted between 380 and $540 \mathrm{~nm}$ in steps of $10 \mathrm{~nm}$.

The synchronous emission spectra were measured in the range of 380-540 nm, with a constant difference of $50 \mathrm{~nm}$ between excitation and emission wavelengths. Their second derivatives were obtained using the AB-2 software.

\section{HPLC analysis}

Heart chloroform extracts were evaporated under the stream of nitrogen. The evaporated sample was then dissolved in approximately $0.5 \mathrm{ml}$ of $80 \%$ acetonitrile in water. $50 \mu \mathrm{l}$ of this solution was applied on C-18 column (4x250 mm, $5 \mu \mathrm{m})$ attached to a JASCO HPLC instrument equipped with fluorescence detector. The detector was set at the excitation of $360 \mathrm{~nm}$ and the emission of $410 \mathrm{~nm}$. The chromatography was run in the linear gradient mode between $20-80 \%$ acetonitrile in water during $40 \mathrm{~min}$. The flow rate was $0.7 \mathrm{ml} \mathrm{min}^{-1}$, the column was thermostated at $30{ }^{\circ} \mathrm{C}$.

\section{Results}

As the first step in our study, we analyzed fatty acid composition of the heart during ontogenesis. The abundances of 13 fatty acids are given in Table 1. The physiological effects are mostly imparted by the ratio of saturated/unsaturated fatty acids. Therefore, the time course of polyunsaturated fatty acids (PUFA) arachidonic acid (20:4, number of carbons:number of double bonds), and docosahexaenoic acid (22:6), is compared to major saturated acid, stearic acid (18:0) in Figure 1. The statistical significance is related to the fetal group. Stearic acid transiently decreased on D1 and then returned to the fetal level on D2 and stayed without change until adulthood. Arachidonic acid significantly decreased on D1 and subsequently rose to reach maximum on D4 and D8, then significantly decreased on 


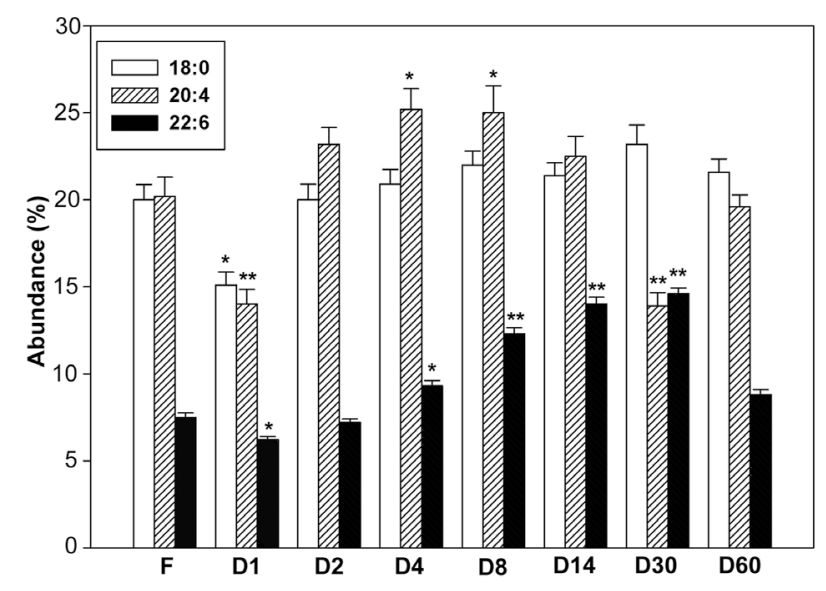

Fig. 1. Abundances of stearic acid (18:0), arachidonic acid (20:4), and docosahexaenoic acid (22:6) in the rat heart lipophilic fraction during development. Statistical significance is related to the fetal group, ${ }^{*} \mathrm{P}<0.05,{ }^{* *} \mathrm{P}<0.01$. For the group description see Materials and Methods.
D30 again. The time course of docosahexaenoic acid differed from that of arachidonic acid: after initial decrease on D1 it steadily rose until D30 when it reached its maximum. On D30 the abundances of both unsaturated fatty acids were the same and on D60 both returned to initial values. This, however, meant an increase in arachidonic acid and a decrease in docosahexaenoic acid. Figure 1 thus illustrates that major changes in fatty acids composition occurred immediately after birth and then during animal maturation.

LFP represent the products of free radical interactions with unsaturated fatty acids. It was therefore interesting to study changes in LFP composition with regard to the changes in the composition of unsaturated fatty acids shown above. The collection of spectral arrays of studied time intervals is shown in Figure 2. It is

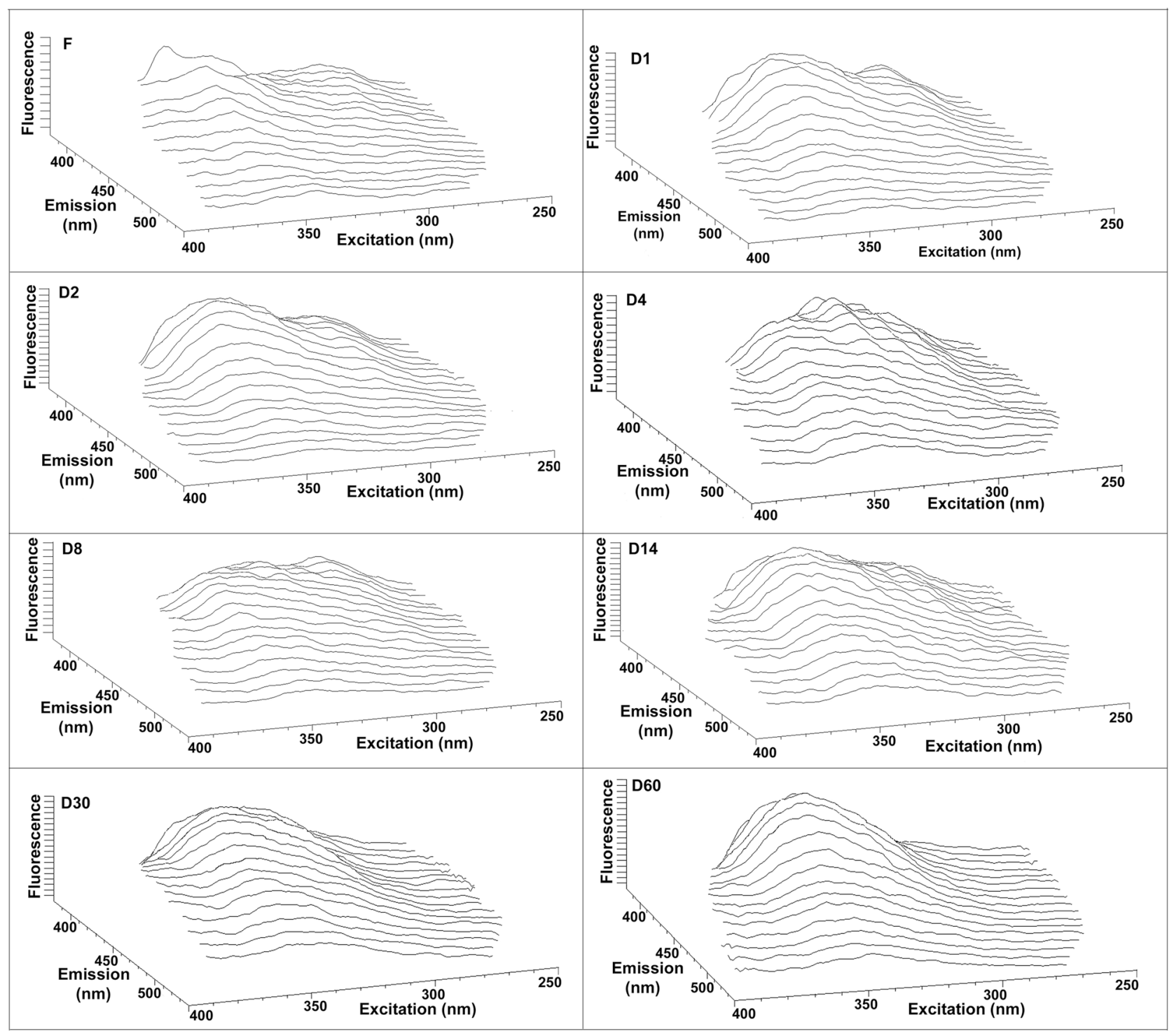

Fig. 2. Tridimensional fluorescence spectral arrays of LFP in the rat heart lipophilic fraction during development. Fluorescence is given in arbitrary units. For the group description see Materials and Methods. 


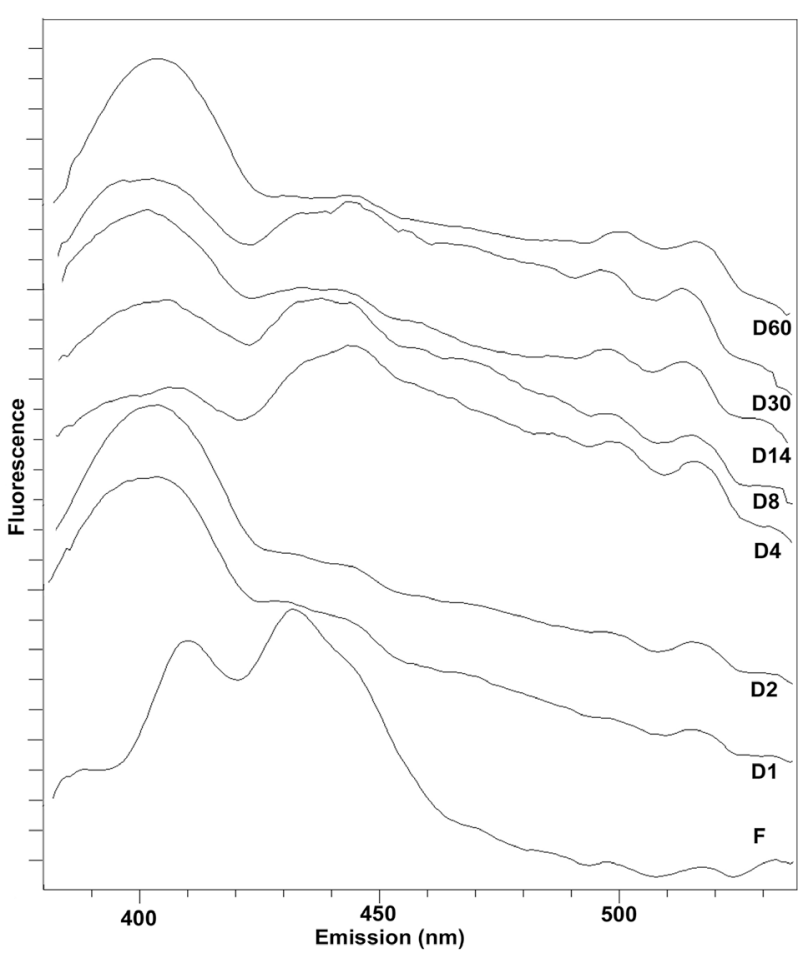

Fig. 3. Synchronous fluorescence spectra of chloroform extracts from rat heart during development. Fluorescence is given in arbitrary units. The same samples as in Figure 2 were used for the measurements.

apparent that immediately after birth on D1 the set of fluorophores differed from the fetal situation. There was no major change on D2, however, dramatic changes occurred on D4 and D8. Starting from D14 there was a steady build-up of the fluorophore with emission around $435 \mathrm{~nm}$ after excitation around $360 \mathrm{~nm}$, which became the predominant species at mature animals on D60.

Synchronous fluorescence spectra are generally used for the characterization of complex mixtures as they represent a "fingerprint" of a given composition. The collection of synchronous spectra of our samples is shown in Figure 3. Similarly as in Figure 2, there is apparent a major difference between fetal samples and those after birth. The "turning points" of changes in the composition are also similar as in Figure 2.

The synchronous spectra can be resolved into individual fluorophores by performing second derivative of the spectra. The results of this mathematical operation are summarized in Figure 4. From these derivative spectra it is apparent that all samples comprise similar set of fluorophores. A quantity of a given fluorophore can be deduced from the depth of a valley corresponding to the emission maximum of this fluorophore. We have chosen fluorophores with emission around $448 \mathrm{~nm}$ (parameter a) and around $517 \mathrm{~nm}$ (parameter b) and used the ratio of b/a to characterize the given time group. The results are shown in Table 2. In the fetal group this ratio is below 1 , in all other groups it is higher than 1 with a local maxima at D2 and D30. The changes in this ratio and the shape of derivative spectra indicate that the spectral characteristics of individual fluorophores are not changed during development, rather, their ratio influences the shape of the synchronous spectra. Apparently no or only a little of new fluorophores have been formed during postnatal development.

The fluorophores characterized spectrally can be further resolved by chromatographic methods. To demonstrate this possibility we have chosen the fluorophore with excitation maximum around $360 \mathrm{~nm}$ and emission maximum around $410 \mathrm{~nm}$ and resolved it by HPLC in all studied groups. The results are illustrated in Figure 5. It can be seen that immediately after birth in group D1 new fractions were observed within retention times of 4-8 min. During further development the ratio of these fractions has been changed, thus indicating alterations in the composition of LFP. A qualitative change occurred on D30, when the major fraction had retention time around $23 \mathrm{~min}$. Further alteration in LFP composition was observed on D60 when the fractions with retention time of 4-8 min were predominant. This analysis also documents that a single spectrally characterized fluorophore comprises several distinct compounds.

\section{Discussion}

Previous studies have shown that remodeling of heart during early development is accompanied by changes in fatty acid profiles in total phospholipids (Gudmundsdottir and Gudbjarnason 1983), and a more detailed study analyzed the fatty acid profiles in individual phospholipid species (Novák et al. 2006). In both studies it was suggested that several factors may play a role in the observed effects, mainly nutrition, metabolic transition, hormonal changes and increasing workload.

During postnatal development of rats two periods were found when major metabolic changes occurred (Ostadal et al. 1999). The first period is observed after birth, when the nutrition changes from high-carbohydrate utilization of the fetus to the high-fat consumption of the neonate provided by the mother's milk. This is accompanied by switch to oxidative metabolism. Especially postnatal day 4 appears to be 
critical for the rat heart development, as cellular proliferation is replaced by the hypertrophic growth that is triggered by increased heart workload (Li et al. 1996), and the value of heart/body weight ratio is the highest (Oštádal et al. 1967, Oštádalová et al. 1993). The second period occurs at the time of weaning when there is a change in both content and composition of dietary fat. It is a change from mother's milk to laboratory chow, i.e. from high fat diet to high carbohydrate diet three weeks after birth.

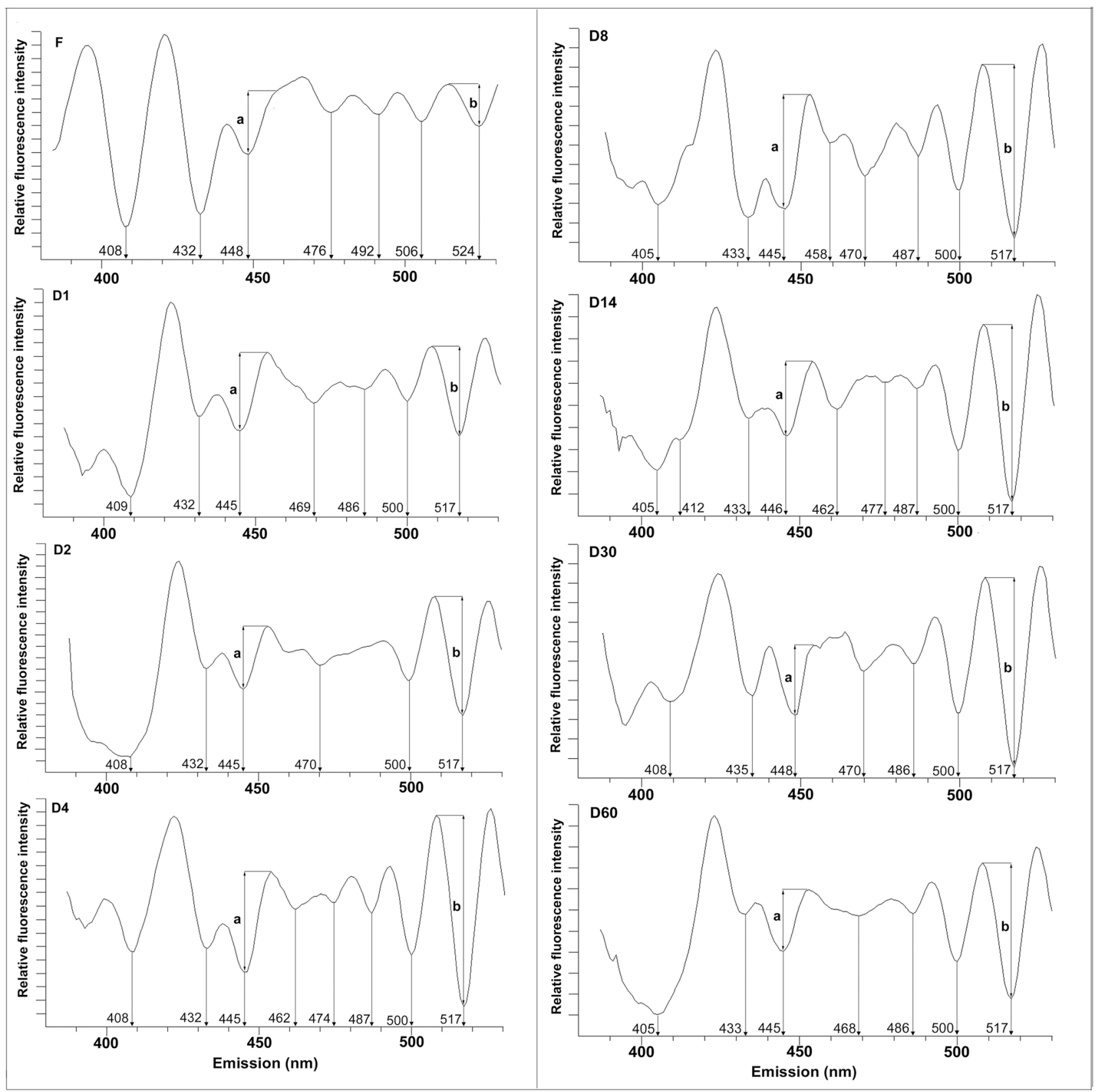

Fig. 4. Second derivatives of the synchronous fluorescence spectra shown in Figure 3. The arrows indicate the emission maxima of the resolved fluorophores, $\mathbf{a}$ and $\mathbf{b}$ are the parameters used for the characterization of the ratio of fluorophore emitting at $448 \mathrm{~nm}$ and $517 \mathrm{~nm}$, respectively.

Table 2. Ratio of parameters b/a obtained from Figure 4 in the course of development.

\begin{tabular}{lllllllll}
\hline Group & F & D1 & D2 & D4 & D8 & D14 & D30 & D60 \\
\hline b/a & 0.7 & 1.2 & 1.9 & 1.4 & 1.5 & 2.4 & 2.7 & 2.2 \\
\hline
\end{tabular}




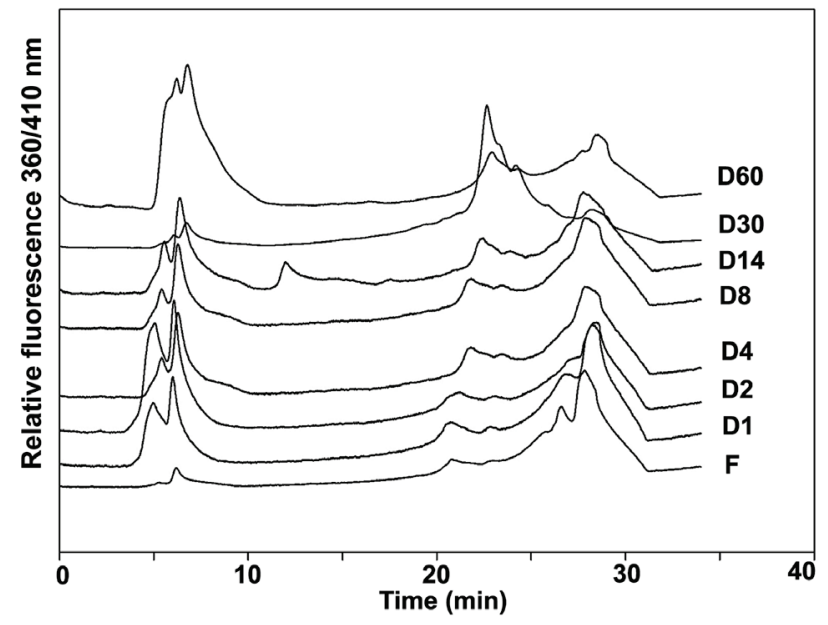

Fig. 5. HPLC analysis of the fluorophore with excitation maximum at $360 \mathrm{~nm}$ and emission maximum at $410 \mathrm{~nm}$ in the course of development. Relative fluorescence is given in arbitrary units, abscissa shows the time of analysis.

In our previous study (Wilhelm and Oštádalová, 2012) we have shown a sharp increase in the heart LFP concentration during the first five postnatal days in relation to the fetal level. This can be taken as a demonstration of the oxidative stress. Therefore, in the present study we used a more detailed sampling during the first two postnatal weeks and enlarged the scope of previous studies (Gudmundsdottir and Gudbjarnason 1983, Novák et al. 2006) to fetal values.

Pronounced increase in the abundance of arachidonic acid in the heart of newborn rats was suggested to reflect the response of the heart to stress associated with transition from fetal to neonatal metabolism (Gudbjarnason 1989). Here we suggest that oxidative stress is another factor playing a role in modulation of fatty acids profile in postnatal heart. Immediately after birth on D1 we observed a sharp decrease in arachidonate and other PUFA abundance that could have been explained by free radical-initiated oxidation, however, from D2 on we found increased abundance of PUFA in agreement with Gudbjarnason (1989) which indicates that large metabolic rearrangements are probably in play that override the consumption of unsaturated fatty acids by free radicals. Consumption of PUFA precedes the development of LFP, thus supporting the idea that PUFA serve as a substrate for LFP formation. In the recent study (Puente et al. 2014) ROS production was found to increase in developing mouse heart from postnatal day 1 to day 7 , when it was maximum, and correlated with DNA oxidative damage. Besides the possibility that ROS production kinetics might differ in different animal species, the sensitivity of PUFA to free radical attack is higher than that of DNA, and therefore changes in PUFA composition occur earlier in development.

Tridimensional fluorescence spectral arrays offer the integral view of the fluorophores present in the measured sample. Even the subtle change in their composition is revealed in the overall pattern. The set of these spectra shown in Figure 2 documents the dynamics of the changes in LFP composition during heart development. The overall pattern is largely modified on D1, D4, D8, and D14, and the spectra of matured animals on D60 can be distinguished from those of young animals. These "turning points" correlate with the critical days of heart postnatal development. It indicates the involvement of LFP in the key developmental stages.

The synchronous fluorescence spectra are widely used for the characterization of complex mixtures (Rubio et al. 1986), as their shape depends on the number of fluorescing species and also on their abundance. Spectra shown in Figure 3 document a qualitative difference between fetal and postnatal heart. Further modifications of the shape of the spectra in postnatal animals correspond to the "turning points" found in the tridimensional spectra.

The second derivative of synchronous fluorescence spectra enables to reveal individual fluorophores "hidden" under the integral curve (Rubio et al. 1986). It is apparent from Figure 4 that heart lipophilic fraction contains the same set of fluorophores since the fetal state till adulthood with only minor modifications of their fluorescence properties. It suggests that the abundance of individual fluorophores is the parameter that has been changing throughout the development. To characterize that, we used the ratio of fluorescence with emission around $445 \mathrm{~nm}$ and around $517 \mathrm{~nm}$. The results shown in Table 2 indicate that the changes are not linear, as we see two local maxima on D2 and D30. The second derivative of synchronous spectra thus documents that the appearance of the overall pattern of the fluorescence spectra is dependent on the ratio of fluorophores present in the heart since the fetal state and that no new major fluorophores are formed in the course of development. Just in the specific time intervals some fluorophores are formed in a greater quantity than the others.

LFP characterized by spectral methods can be resolved into individual species by HPLC techniques. By this way we were able to recognize several tens of fluorescent LFP species in the developing brain (Wilhelm et al. 2011). In the present study we have demonstrated 
the capability of HPLC method in separation of the heart fluorophore with excitation maximum at $360 \mathrm{~nm}$ and emission maximum at $410 \mathrm{~nm}$. New chromatographically distinct species appeared immediately on D1 and major changes in the chromatography pattern occurred on D30 and D60 that could be related to changes in PUFA abundances. It illustrates the complexity of the problem, as not only the ratio of fluorophores is being changed, but also the species carrying them are modulated in the course of heart development.

Taken together, all the used methods document dynamic changes in the composition of LFP during development. As LFP are indicators of free radical oxidative damage, we can deduce that oxidative stress and its consequences play a role at specific points of the development. What is the actual role of LFP, however, is not clear and should be aimed in the next studies.

\section{Conflict of Interest}

There is no conflict of interest.

\section{Acknowledgements}

This work was supported by grant of GACR No. P303/11/0298.

\section{References}

CSALLANY AS, AVAZ KL, MENKEN BZ: Organic solvent soluble lipofuscin pigments and glutathione peroxidase in weanling and old rats. Int J Vitam Nutr Res 56: 143-147, 1986.

DEL ROSO A, DE TATA V, GORI Z, BERGAMINI E: Transmural differences of lipofuscin pigment accumulation in the left ventricule of rat heart during growth and aging. Aging (Milano) 3: 19-23, 1991.

DODGE JT, PHILLIPS GB: Composition of phospholipids and of phospholipid fatty acids and aldehydes in human red cells. J Lipid Res 8: 667-675, 1967.

GERCKEN G, TILING T, BROCKMANN U, SCHROTER W: Fatty acid composition of phospholipids in erythrocytes of adults, normal newborn infants, and neonates with Rh erythroblastosis. Pediatr Res 6: 487-494, 1972.

GOLDSTEIN BD, MCDONAGH EM: Spectrofluorescent detection of in vivo red cell lipid peroxidation in patients treated with diaminodiphenylsulfone. J Clin Invest 57: 1302-1307, 1976.

GUDBJARNASON S: Dynamics of n-3 and n-6 fatty acids in phospholipids of heart muscle. J Intern Med 225 (Suppl): 117-128, 1989.

GUDMUNDSDOTTIR A, GUDBJARNASON S: Neonatal changes in fatty acid profile of phospholipids in rat heart muscle. Biochim Biophys Acta 752: 284-290, 1983.

IKEDA H, TAUCHI H, SHIMASAKI H, UETA N, SATO T: Age and organ difference in amount and distribution of autofluorescent granules in rats. Mech Ageing Dev 31: 139-146, 1985.

IVICA J, WILHELM J: Lipophilic fluorescent products of free radicals. Biomed Pap Med Fac Univ Palacky Olomouc Czech Repub 158: 365-372, 2014.

JAMIESON DD: Lipid peroxidation in brain and lungs from mice exposed to hyperoxia. Biochem Pharmacol 41: 749$756,1991$.

KUMA A, HATANO M, MATSUI M, YAMAMOTO A, NAKAYA H, YOSHIMORI T, OHSUMI Y, TOKUHISA T, MIZUSHIMA N: The role of autophagy during the early neonatal starvation period. Nature 432: 1032-1036, 2004.

LI F, WANG X, CAPASSO JM, GERDES AM: Rapid transition of cardiac myocytes from hyperplasia to hypertrophy during postnatal development. J Mol Cell Cardiol 28: 1737-1746, 1996.

MITCHELL JA, VAN KAINEN BR: Effects of alcohol on intrauterine oxygen tension in the rat. Alcohol Clin Exp Res 16: 308-310, 1992.

MUSCARI C, CALDARERA CM, GUARNIERI C: Age dependent production of mitochondrial hydrogen peroxide, lipid peroxides and fluorescent pigments in the rat heart. Basic Res Cardiol 85: 172-178, 1990.

NOHL H, HEGNER D, SUMMER KH: The mechanism of toxic action of hyperbaric oxygenation on the mitochondria of rat-heart cells. Biochem Pharmacol 30: 1753-1757, 1981.

NOVÁK F, TVRZICKÁ E, HAMPLOVÁ B, KOLÁŘ F, NOVÁKOVÁ O: Postnatal development of phospholipids and their fatty acid profile in rat heart. Mol Cell Biochem 293: 23-33, 2006. 
OŠŤÁDAL B, WACHTLOVÁ M, BÍLÝ J, RAKUŠAN K, POUPA O: Weight of the heart in rats before and after birth. Physiol Bohemoslov 16: 111-115, 1967.

OSTADAL B, OSTADALOVA I, DHALLA NS: Development of cardiac sensitivity to oxygen deficiency: comparative and ontogenetic aspects. Physiol Rev 79: 635-659, 1999.

OŠŤÁDALOVÁ I, KOLÁŘ F, OŠŤÁDAL B, ROHLÍČEK V, ROHLÍČEK J, PROCHÁZKA J: Early postnatal development of contractile performance and responsiveness to $\mathrm{Ca}^{2+}$, verapamil and ryanodine in the isolated rat heart. J Mol Cell Cardiol 25: 733-740, 1993.

OŠŤÁDALOVÁ I, VOBECKÝ M, CHVOJKOVÁ Z, MIKOVÁ D, HAMPL V, WILHELM J, OŠŤÁDAL B: Selenium protects the immature heart against ischemia/reperfusion injury. Mol Cell Biochem 300: 259-267, 2007.

OŠŤÁDALOVÁ I, CHARVÁTOVÁ Z, WILHELM J: Lipofuscin-like pigments in the rat heart during early postnatal development: effect of selenium supplementation. Physiol Res 59: 881-886, 2010.

PUENTE BN, KIMURA W, MURALIDHAR SA, MOON J, AMATRUDA JF, PHELPS KL, GRINSFELDER D, ROTHERMEL BA, CHEN R, GARCIA JA, SANTOS CX, THET S, MORI E, KINTER MT, RINDLER PM, ZACCHIGNA S, MUKHERJEE S, CHEN DJ, MAHMOUD AI, GIACCA M, RABINOVITCH PS, AROUMOUGAME A, SHAH AM, SZWEDA LI, SADEK HA: The oxygen-rich postnatal environment induces cardiomyocyte cell-cycle arrest through DNA damage response. Cell 157: 565-579, 2014.

RANDERATH E, ZHOU GD, RANDERATH K: Organ-specific oxidative DNA damage associated with normal birth in rats. Carcinogenesis 18: 859-866, 1997.

RUBIO S, GOMEZ-HENS A, VALCARCEL M: Analytical applications of synchronous fluorescence spectroscopy. Talanta 33: 633-640, 1986.

SASTRE J, ASENSI M, RODRIGO F, PALLARDO FV, VENTO M, VINA J: Antioxidant administration to the mother prevents oxidative stress associated with birth in the neonatal rat. Life Sci 54: 2055-2059, 1994.

SHIMASAKI H: Assay of fluorescent lipid peroxidation products. Methods Enzymol 233: 338-346, 1994.

TVRZICKÁ E, VECKA M, STAŇKOVÁ B, ŽÁK A: Analysis of fatty acids in plasma lipoproteins by gas chromatography-flame ionization detection: quantitative aspects. Anal Chim Acta 465: 337-350, 2002.

VASANKARI T, KUJALA U, HEINONEN O, KAPANEN J, AHOTUPA M: Measurement of serum lipid peroxidation during exercise using three different methods: diene conjugation, thiobarbituric acid reactive material and fluorescent chromolipids. Clin Chim Acta 234: 63-69, 1995.

WEBSTER WS, ABELA D: The effect of hypoxia in development. Birth Defects Res C Embryo Today 81: 215-228, 2007.

WILHELM J, HERGET J: Hypoxia induces free radical damage to rat erythrocytes and spleen: analysis of the fluorescent end-products of lipid peroxidation. Int J Biochem Cell Biol 31: 671-681, 1999.

WILHELM J, OŠŤÁDALOVÁ I: Ontogenetic changes of lipofuscin-like pigments in the rat heart. Physiol Res 61 (Suppl 1): S173-S179, 2012.

WILHELM J, IVICA J, KAGAN D, SVOBODA P: Early postnatal development of rat brain is accompanied by generation of lipofuscin-like pigments. Mol Cell Biochem 347: 157-162, 2011. 